\title{
Initiating Mobile Phone Technology using QR Codes to Access Library Services at the University of Cape Town
}

Shehaamah Mohamed

University of Cape Town

\begin{abstract}
This article reports on an innovative project which grew out of the desire to facilitate access to information using the Quick Response (QR) Code. Easily read by mobile phones with cameras, the QR Code provides a simple but effective means for library patrons to access library resources. The article explores the need to use the QR Code in the Brand van Zyl Law Library, University of Cape Town (UCT), for accessing academic library services. Although relatively new in South Africa, QR Codes have been used successfully by some local educational institutions. Against this background, the article reports on a needs analysis which was conducted at the Brand Van Zyl Law Library and recommends the accelerating use of QR Codes in the academic environment.
\end{abstract}

Keywords: QR codes, mobile technology, mobile phones, mobile phone technology, academic libraries

Corresponding author: Shehaamah Mohamed, Subject Librarian: Brand van Zyl Law Library, Wilfred \& Jules Kramer Law Building, Off Woolsack Drive, Rosebank, Middle Campus, University of Cape Town (UCT),Email: Shehaamah.Mohamed@uct.ac.za

\section{Introduction and background to the study}

Advances in the progression of information technology are rapidly changing the patterns of communication (Kwanya et al 2009) amongst library users and subsequently, their expectations about the composition of libraries are also undergoing transformation. It is suggested that new technologies offer easier access to information and electronic resources, for instance, individuals find it easier to Google (http://www.google.com) and search for information than to consult their nearest library. Since the digital environment has become the new information ecosystem for the $21^{\text {st }}$. century library patron, librarians have to manage these changes and respond to the manifestations of Web 2.0 in order to efficiently meet research needs. The latest developments in technologies have also resulted in the emergence of Web 3.0 as well as the advent of Web 4.0, both which will play a significant role in the future of libraries. While Web 2.0 represents a major shift in the way users view the web "from a read-only web to a read-write web" (Stuart, 2010), Web 3.0 offers virtual $3 \mathrm{D}$ worlds which enable users to interact with one another. This platform of virtual interaction has, according to Stuart (2010), been recognized by many information professionals as new ways of seeking information. 
Web 2.0 encompasses Library 2.0, the latter being the application of interactive, collaborative and multi-media web-based technologies to library services and collections (Kwanya et al 2009:72). Evans (2009) maintains that interactivity and mobility are the most active features of Library 2.0 and are evident in the subsequent changes that are taking place in the information seeking behaviour of the new library user. This "mobility of information" (Evans 2009:26) has altered the manner in which the users engage in research. Information is now available via websites and mobile devices such as tablet computers and cellphones, enabling the user with instant access.

Kwanya et al list a number of principles of Library 2.0 librarianship. The Library 2.0 domain should ideally manifest itself in a physical library which has no barriers and where the use and re-use of resources should be permitted and encouraged. Wider user communities, staff and technology partners are invited to participate in this new barrier-free library by the use of wikis, blogs and Rich Site Summary (RSS) Feeds which are currently on Web 2.0 platforms (Kwanya et al 2009:72). More significantly, the digital library should be everywhere. This means that information services should ideally be provided at the point of need. To accomplish this, library services should be visible on a wide range of devices (Kwanya et al 2009:72) which includes the use of mobile phone technology.

Although the literature is permeated with the importance of ICT and mobile technologies in university libraries, very little has been written on the impact of the QR Code in academic research in South Africa. Against this background, the research aims to cover this omission and focuses on the widespread and accelerating use of QR Codes in libraries via the use of mobile phones. The conceptual framework for the study is drawn from the contributions of Kwanya et al (2009) and Evans (2009) and from developments in mobile phone technology.

Mobile phone technology is rapidly infiltrating the African physical and information environments. According to Jan Hutton, Director, Telecoms, Nielsen Southern Africa (2011), more Africans have access to mobile phones than to clean drinking water. In South Africa, the continent's strongest economy, mobile phone use has gone from 17 percent of adults in 2000 to 76 percent in 2010. Today, more South Africans - 29 million - use mobile phones than radio ( 28 million), television (27 million) or personal computers (6 million). Only 5 million South Africans use landline phones (Hutton 2011).

It has been postulated that the smartphone will be the primary source of Internet access for most people in the world by the year 2020 (Mullan 2012). It can be categorized as a miniature computer which provides information in the palm of your hand. An analysis of the literature reveals that librarians are encouraged to become involved with mobile phone technologies as a means of providing access to library services. Until fairly recently, the academic library had been the physical domain 
which the researcher would frequent for information and where library patrons had to be sitting at desktop computers to be able to download electronic files. However, with the explosion of mobile phone technology, patrons and researchers are increasingly expecting library services to come to them in the form of electronic resources which can easily be accessed on their phones. The literature discloses that today's university students are much more versatile in their use of mobile devices and the Internet than are the older generation. Hutton (2011) claims that the mobile phone is increasingly being used as an internet device, that "11 per cent of South Africans use their mobiles to go online, and that consumers aged 25-34 are the heaviest users" (Hutton, 2011:1). Citing one of the leading polling firms in the United States, Lippincott (2008) maintains that academic students prefer to use the internet to watch television and listen to the radio and that "they are less likely to dismiss the usefulness of the information on small screens" than our predecessors (Lippincott 2008:1).

With the proliferation of mobile technologies, it is desirable that such technologies be utilized to expedite access to scientific materials. This study on QR Codes aims to facilitate access to library resources and relates to the research domain of the developing world, especially as the latter "remains at a disadvantage in terms of both the production and distribution of knowledge" (Mohamed 2009:69). It is therefore imperative that libraries serve as a platform for becoming part of the patron's information ecosystem (Griffey 2010) and offer a portable service which reaches them instantly irrespective of their location. Andrew Walsh proposes that library services be made available to patrons "at the real point of need" (Walsh 2010: 57). Online assistance should be linked to and displayed from strategic areas in the library where students tend to search for information. The overarching objective for introducing mobile phone technologies in the research domain is to make a connection between the physical library and the virtual one.

\section{The QR Code: linking library patrons to e-resources}

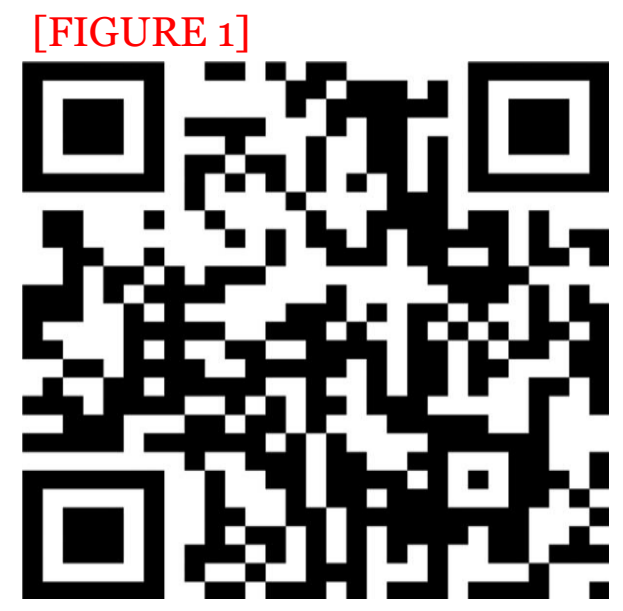

Figure 1: QR code for the Brand van Zyl Law Library website. 
Developed in Japan during 1994 by Denso Wave, the QR Code is a barcode capable of accessing data and can be read with most smartphones and mobile phones with cameras. It appears as a small white square with black geometric shapes and holds much more information than a regular barcode. The QR Code was initially used by a Toyota subsidiary to track their vehicle parts inventory (Elmore et al 2012) but soon it became fashionable in advertising. For instance, QR Codes have been deployed in marketing campaigns, job advertisements, fliers and public notices in Japan and Korea for many years (Evans 2010). They are also attached to food items such as fruit and vegetables which, when scanned, provide information where the product was sourced from and where it was grown (Elmore at al 2012).

\section{How are QR Codes generated and deciphered?}

QR Codes are very easy to generate by using online QR Code reader systems such as Kaywa (http://qrcode.kaywa.com/) where a code is made instantaneously. The procedure is free of charge and no specialist technical skills are required to create the message. The QR Code is therefore a financially viable research tool. The Kaywa generator allows four different content types - a URL, text, phone number or SMS. After choosing the content type, the creator (the librarian in this case) formulates her message and adds a URL or other data followed by clicking on the "generate" button. The end product resembles the illustration in Figure 1.

To read QR Codes, users must have downloaded either of the QR Code readers, Beetagg (http://get.beetagg.com/ : Figure 2) or I-nigma (www.i-nigma.mobi: Figure 3) to their phones.

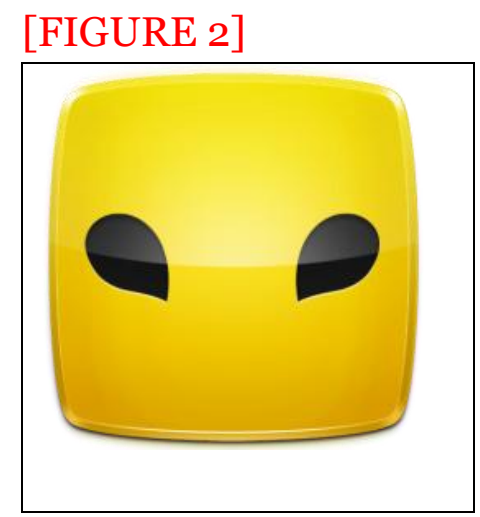

$\begin{array}{llllll}\text { Figure } & 2 . & \text { Beetagg } & \text { QR } & \text { Code } & \text { Reader. }\end{array}$ Source: reproduced with permission from Beetagg Support Team, Connvision Ltd., Zürich, Switzerland. 


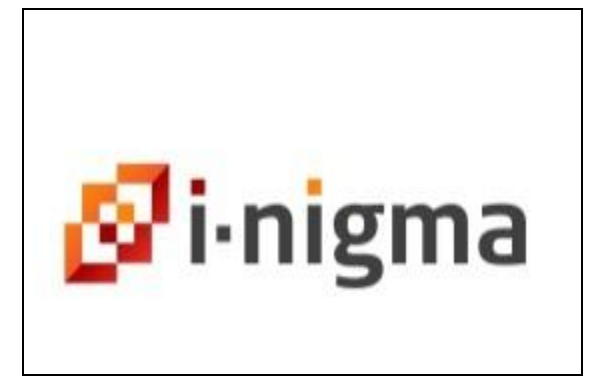

Figure 3. I-nigma QR Code Reader.

Source: reproduced with the permission from Ofer Lev, $3 \mathrm{G}-\mathrm{Vision}$.

The QR barcodes have blocks of black and white pixels arranged in such a way that a mobile phone's camera can recognize them, align them and pull data from what may seem like random checkers to the human eye (Evans 2009:80). The user places the phone over the QR Code; the camera opens up and reads the code instantly. The data is then loaded as a webpage, text message or as an image.

Surveys on current technology trends reveal that library services still remain out of sync with user expectations (Elmore et al 2012). Students at academic institutions expect a service which is 'custom-made' to meet their research requirements; hence libraries have actively begun to repackage their services for the emerging mobile client. According to Ashford, QR Codes are making huge inroads in the United States (Ashford 2010) and globally. She cites an online best practice wiki which explains how libraries have implemented QR Codes. Also known as two-dimensional barcodes, QR Codes have been used for a multitude of services such as accessing research guides, providing links to mobile websites, placing them on books to recommend further reading, providing links to virtual library tours and even embedding them in items in journal stacks to direct patrons to the electronic version on open access journal sites ("QR Codes-Library Success: A Best Practice Wiki", 2012. Against this background and rationale for the use of $Q R$ codes, the researcher introduced the QR Code to library patrons at the Brand van Zyl Law Library, UCT. The results have been evaluated and are discussed below.

\section{Literature analysis}

The literature reveals that a multitude of beneficial uses for QR Codes have been identified. Librarians and staff in large research universities, small liberal arts institutions and museums are experimenting with and using QR Codes in both their physical and online libraries (Ashford 2010).

The potential uses for QR Codes have been recognized by various educational institutions, many of which have been extended to the classroom (Robertson and Green 2012). Essentially, the $Q R$ Code is seen as a mechanism to bridge the gap between paper and the web. QR Codes may be affixed in posters for multimedia school projects where students can scan the codes and view videos and animations. 
Similarly, teachers could embed QR Codes in their teaching slides for students who require supplemental support. Robertson explains that in this instance, students with special needs could snap a pick of the QR Code and get the materials they need for the class and avoid having to wait for additional group time.

Tucker (2011) offers his article as an inspiration for fellow technology and engineering educators. Students at the Center for Arts and Technology-Pickering Campus, Phoenixville, created the QR Code Yearbook Project. Using QR Codes, students were able to include coverage of their prom, awards and graduation ceremonies. Instead of featuring still pictures, QR codes are placed on certain pages which, when scanned, depict videos and animation. The school is planning to expand the use of QR Codes in their newsletters, where additional coverage of talent shows and sport events will be featured.

The University of Amsterdam Library uses QR Codes to promote their mobile library catalogue by appending the code to their promotional materials (Ashford 2010). The Florida State University Law Library utilizes QR Codes for contact information of reference librarians. QR Codes are also being displayed in the stacks to assist library patrons who want to locate the electronic format of a printed resource (Jackson 2011). In addition, bookmarks with QR Codes lead patrons to law databases, legal research guides and the library's blog.

Jackson (2011) contends that if libraries are meant to be of any value to library users in the technological age, patrons have to be linked with information in new ways. It is imperative that libraries become increasingly aware of changing technologies, that they update their library services in this regard and more importantly, that they maintain awareness of user needs and their use of these technologies. Various university libraries had therefore performed a number of surveys to ascertain user experience of the QR Code in order to improve their services.

User needs assessments such as that of Hicks and Sinkinson (2011) reveal that there are many pitfalls involved with using QR Codes. According to these researchers, the major drawback is lack of awareness of these codes. A survey conducted by Ramsden and Jordan (2008) found that approximately 15 percent of the total student population at the University of Bath, United Kingdom (UK), indicated that they are aware and have heard of QR Codes. The fact that nine out of 10 students were unaware of $\mathrm{QR}$ Codes meant that the university should start implementing appropriate support mechanisms such as training programmes if students are to use these codes. Their findings indicated that although 91 percent of participants owned camera phones, only a small percentage of students had ever used their phones to scan QR codes.

However, Hicks and Sinkinson (2011) conclude that although there is little awareness and usage of QR codes, there is potential for more widespread use. This is evident in 
a follow-up survey which took place in 2009. The survey, which was performed at the University of Huddersfield, UK, showed that before the Library advertised and exhibited QR Codes as a means of accessing library resources, only 8 percent of respondents were familiar with QR codes. After one term of using QR Codes in the library, the percentage increased to 22 percent. These findings emphasize that user education in QR Codes is essential.

The Hicks and Sinkinson (2011) study at the University of Colorado at Boulder Libraries reveals that QR Codes are flexible and can reach all students. If placed strategically, usage can increase dramatically. This finding is supported by the efforts employed by the University of Pretoria (UP) Library. An e-strategy team was established to initiate a QR Code marketing strategy. QR Codes were used to market the Library's new mobile website. Laminated posters depicting QR Codes were put up at the circulation desks, library stacks, and leisure reading collection nooks and even in lifts. A short guide accompanied each poster explaining what a QR Code is and how it can be read. Student responses were overwhelming despite the fact that no formal training was offered. Access to the mobile website and usage rates accelerated within weeks which confirmed the success of QR Codes as marketing tools (Ehlers 2012).

The literature theorizes that the QR Code has been welcomed as a mechanism for information retrieval. It is thus being extensively used in international libraries such as those at the universities of Huddersfield and Bath in the UK and academic libraries in the USA and Canada. These case studies provided a further impetus for this pilot project.

\section{Research aims and questions}

The aim of this research was to examine the practicability of using QR Codes at UCT's Brand van Zyl Law Library. The needs analysis therefore aimed to:

1. Determine the number of law students who have and use smartphones and to document the frequency with which they use their phones for academic research.

2. Determine whether law students are familiar with QR Codes and assess the likelihood that they would elect to use QR Codes for research.

3. Evaluate the reasons why law students would be in favour of using the QR Code in the law library.

\section{Overview of the research methodology and design}

The project employed a case study approach to examine the use of QR Codes at the Brand van Zyl Law Library, UCT. The case study research method is generally defined as an "empirical inquiry that investigates a contemporary phenomenon within its real-life context" (Soy 1997) by employing questions that focus on that particular phenomenon or object. The advantage attached to the case study research 
approach is that it may be applied to contemporary, human situations and is publicly accessible through written reports. It is posited that the case study approach is an appropriate methodology to use in library studies (Soy 1997) and that this method could further be used to study the role that librarians play in implementing new models of service. Hence, through observations and feedback gathered from students this case study sought to identify effective implementation strategies for the use of QR Codes.

\section{The study comprised three steps. Step 1: the needs analysis}

First, a needs analysis was performed whereby an information sheet about QR Codes attached to a short questionnaire with a maximum of 10 questions was distributed to students. Titcomb describes a needs analysis as the process of identifying and evaluating needs in a community or other defined population of people such as library users and it is essentially used to determine the gap between "what is" and "what should be" (Titcomb 2000). The term 'needs assessment' may also be used as a related concept to describe this form of methodology.

The law student community was identified as the target audience for this study and the motivation for having performed a needs analysis was to ascertain what information they require in order for the law library to provide it in the quickest and most inexpensive manner possible. In order to reach ample law students, the researcher, in her capacity as Webmaster of the law library, also placed the questionnaire on the law library home page at the following link: http://www.lib.uct.ac.za/law, inviting students to participate and submit the completed questionnaire at the circulation desk. With the commencement of the second academic semester, the researcher employed additional methods to market the QR Code survey:

1. Note tags were placed on all the desktop computers in the law library which reminded students to complete the QR code survey.

2. An email was sent to all academic staff in the Law Faculty appealing for their assistance. They were asked to remind students during their lecture periods to complete the survey on the Law Library website. An announcement was placed on the law student communication tool, Vula, which is accessible by all registered law students.

More than 100 questionnaires were distributed of which 50 (which include online submissions) were returned to the researcher. After data was gathered, an assessment was done whereby the needs were evaluated, sifting those needs which appeared to be more important from those which were less urgent. 


\section{Step 2: Staff training and the production of a training manual}

As the study is the first of its kind to be performed at UCT Libraries, librarians at the Brand van Zyl Law Library had to be introduced to, informed about and updated on the newest mobile technologies, in particular the QR Code. The researcher therefore prepared a training manual on QR Codes in the form of a wiki for the law library staff (QRCodeslawlibrary.wikispaces.com). Similarly, the researcher created a QR Codes library training guide (LibGuide) for students which they could access on the home page at http://libguides.lib.uct.ac.za/qr-codes-law .

It is envisioned that ample feedback will be elicited via these tools which will prove to be significant for the second survey. As time elapses students will be invited to post comments about their experiences with QR Codes on the law library blog (http://lawlibraryuct.blogspot.com/), which was designed for this study's purpose.

\section{Step 3: The QR Code competition and second survey}

A QR Code competition will be held at the Law Library during 2013. This step will further encourage library patrons to use QR Codes as a research tool in the library. A subsequent larger survey will be conducted as a means of gauging student receptivity and interest in QR Codes. A self-administered paper comprising 20 questions will be used to collect the data.

\section{Data analysis}

Data for the needs analysis was analysed using simple frequency counts and percentages for closed questions and thematic analysis for responses from open questions. The concept of thematic analysis was historically coined as a practice which involves "searching through data to identify any recurring patterns" (The process of thematic analysis, 2010:1). This analytic process involves transcribing theoretical questions into text and identifying emerging themes from the text. It essentially differs from the interpretation of closed questions where the frequency of themes are counted and used to "statistically test any hypothesis" (The process of thematic analysis, 2010:1). The results of the thematic analysis are presented and included in the discussion below.

Pilot QR Code project at Brand van Zyl Law Library: research procedures, results from Step 1 and evaluation of needs analysis findings The QR Code was advertised through the traditional use of posters in the library as well as by means of an information sheet that was attached to the survey questionnaire. The researcher encouraged students to participate by offering a lollipop or chocolate with each copy of the questionnaire. Using this incentive, the study elicited fifty responses during the June vacation - a period when very few students frequent the library. Notwithstanding the difficulty associated with reaching the entire body of law students, the survey managed to produce the following findings: 


\section{Are law students using their smartphones to scan QR Codes for academic research?}

Table 1. Library patrons do not necessarily use their smartphones for research.

It became apparent through responses from the pool of participants that students are generally unfamiliar with QR Codes; at least until they had participated in the needs assessment. The findings suggest that although 74 percent of the respondents own smartphones, 60 percent of respondents have never used their phones for academic research. However, it can be deduced that as a significant percentage of students own the relevant technology, this could mean that few or no barriers should exist within the actual technology which could impede the successful use of QR Codes in this academic library. Similar findings were made in a study conducted at the University of Bath, UK, in 2009 which showed that an overwhelming majority of participants owned smartphones, but were unfamiliar with QR Codes. In the Bath study after QR Code awareness schemes were run a second survey was conducted in 2010, this time indicating a 26 percent increased awareness of QR Codes across the library (Elmore et al 2012:33).

To what extent and how often are law students using their phones to access electronic resources?

[TABLE 1]

\begin{tabular}{|l|l|l|}
\cline { 2 - 3 } \multicolumn{1}{c|}{} & Numbers & Percentages \% \\
\hline Academic use: No & 30 & 60 \\
\hline Academic use: Yes & 20 & 40 \\
\hline Owns a smartphone & 12 & 24 \\
\hline $\begin{array}{l}\text { Does not own a } \\
\text { smartphone }\end{array}$ & 37 & 74 \\
\hline
\end{tabular}

Table 1. Library patrons do not necessarily use their smartphones for research.

[TABLE 2]

\begin{tabular}{|l|l|l|}
\cline { 2 - 3 } \multicolumn{1}{c|}{} & Numbers & Percentages \% \\
\hline Daily & 12 & 24 \\
\hline Weekly & 10 & 20 \\
\hline Monthly & 3 & 6 \\
\hline Never & 25 & 50 \\
\hline
\end{tabular}

Table 2. Frequency of mobile phone use by students using the law library. 
From the evaluative survey conducted it transpires that 50 percent of the participants never access electronic resources via their phones (Table 2). It may be inferred that for many, this may be due to lack of confidence with new mobile phone technology. Loren McDonald theorises that QR Codes in emails [and on posters or items in the library collection] may 'look cool' but could be much more complicated than clicking a link (McDonald 2012). He provides an interesting discussion surrounding key factors to be considered before introducing QR Codes or any new mobile phone technology to a potential market. According to McDonald, the most crucial question to consider is whether QR Codes are available to anyone with Internet access or do users have to overcome an additional barrier to acquire such access? The two practical considerations for QR Codes are first, that users must have smartphones and second, that they must have downloaded a QR Code reader. These factors could contribute to the reasons why few law library patrons use their smartphones to scan QR Codes. In addition, it should be noted that the results of this survey do not encompass the wider constituency of law students and that a more extensive follow-up study should be done. Therefore, the fact that 24 percent of students do indeed access resources on a daily basis (Table 2) coupled with the fact that 60 percent of students own but do not use their smartphone for academic purposes (Table 1) suggests the need for libraries to introduce QR Codes to attract library users.

A new study from a research company, World Wide Worx, confirms that Internet use in South Africa had grown by 25 percent in the past year because of effective smartphone and mobile phone usage (Mobile pushes Internet to the masses 2012). Approximately 6 million people in SA receive Internet through laptops and tablets and 90 percent use their mobile phones. Libraries cannot ignore this growing trend which is a strong indication that QR Codes could and should be used to enhance its services. This point is borne out by Table 3 below, which affirms that technology use for research and information dissemination is accelerating and that it is the preferred mode of engagement amongst academic students.

[TABLE 3]

\begin{tabular}{|l|l|l|}
\cline { 2 - 3 } \multicolumn{1}{c|}{} & Numbers & Percentages \% \\
\hline Yes & 45 & 90 \\
\hline No & 5 & 10 \\
\hline Very Likely & 29 & 58 \\
\hline Maybe & 13 & 26 \\
\hline Not Likely & 8 & 16 \\
\hline
\end{tabular}

Table 3. Probability of using QR Codes in the Law Library. 


\section{The value of $Q R$ Codes: do they fit the library user's context?}

The explanatory notes on QR Codes that were provided with each questionnaire were easily comprehended as 90 percent of the participants indicated that they subsequently understood what QR Codes are and how they can be used (Table 3). Of those who found the information useful, the greater percentage ( 58 percent) of respondents replied that they would most likely use QR Codes for library assistance.

It is worth noting that an insignificant number of respondents did not, however, fully grasp the concept of the QR Code and subsequently failed to understand its purpose. A few students experienced difficulty with downloading the QR Code reader software onto their phones; hence they were not impressed with the functionality that this tool possesses as they were unable to read the QR Code on the survey questionnaire. It stands to reason that these negative responses are due to possible barriers which may be encountered with the use of QR Codes. The enthusiasm which is initially felt when trying to frame a code on one's smartphone may eventually lose its lustre (Barocas 2012). Other factors which may contribute to the disuse of QR Codes may be "inadequate technology, lack of education and a perceived dearth of value from QR codes"(Barocas 2012). Consequently, library users may lose overall interest in this mode of research.

\section{[TABLE 4]}

\begin{tabular}{|l|l|}
\cline { 2 - 2 } \multicolumn{1}{c|}{} & Numbers \\
\hline Links/Url to Law websites & 28 \\
\hline Law databases & 35 \\
\hline Library Tutorials & 9 \\
\hline Law LibGuides & 12 \\
\hline New Books & 20 \\
\hline Staff Contact Details & 16 \\
\hline Exam Dates and Venues & 24 \\
\hline Library Policies & 3 \\
\hline All of the above & 6 \\
\hline None of the above & 3 \\
\hline Other, please specify ... & 0 \\
\hline
\end{tabular}

Table 4: Selected uses for QR Codes

When asked which library services they would want to access via QR Codes, 70 percent of respondents indicated that they would prefer to access law databases, followed by 56 percent who wished to access useful law-related websites (Table 4). It may be deduced that as only 6 percent of respondents said that they would use QR Codes to access library policies, this technology should be ideally used as a channel for research. Alerting library patrons for example, that group study rooms should be booked in advance probably would not be of much benefit as this policy could be communicated at the information desk. However, a QR Code which is pasted next to 
a journal that links to an online electronic version of that journal using a specific open access database would prove to be much more useful to the law student. QR Codes which are located near library materials can quickly and easily bridge the gap between offline research and online resources.

The researcher's ultimate objective for introducing mobile phone technologies at Brand van Zyl is to make the law library webpage mobile friendly. The idea of creating a mobile site is desirable but it will be a costly and time-consuming enterprise. A survey conducted among the 95 academic university libraries in Canada in October 2010 found, for example, that only 14 percent of library websites had any content that was specifically tailored to the use of mobile devices (Elmore et al 2012:30). Research shows that QR Codes are much more valued if they link to websites which are optimized for mobile use (Goodman 2012).

As mentioned earlier, the use of QR Codes is not expensive and will expedite research for the library user. From the above statistics it may be inferred that the implementation of a QR Code programme would facilitate the use of databases and websites as well as electronic resources, thereby fostering the urgency to create a mobile law library website.

\section{Why would law library patrons scan QR Codes?}

\begin{tabular}{|l|l|l|}
\cline { 2 - 3 } \multicolumn{1}{c|}{} & Numbers & Percentages \% \\
\hline Efficiency & 11 & 27.5 \\
\hline $\begin{array}{l}\text { Be updated with advance } \\
\text { technologies }\end{array}$ & 3 & 7.5 \\
\hline Quick and Easy access & 22 & 55 \\
\hline Mobility & 1 & 2.5 \\
\hline $\begin{array}{l}\text { QR Codes to be used for vital } \\
\text { library resources only }\end{array}$ & 1 & 2.5 \\
\hline $\begin{array}{l}\text { Use QR Codes but continue } \\
\text { with conventional ways of } \\
\text { research }\end{array}$ & 1 & 2.5 \\
\hline $\begin{array}{l}\text { Good to use in the event of a } \\
\text { power outage }\end{array}$ & 1 & 2.5 \\
\hline
\end{tabular}

Table 5: Reasons for scanning QR Codes

The inspiration that this study offers is that it is technology based and that 90 percent of participants believe that the law library should implement this method of mobile technology. As QR Codes allow you to tag physical objects such as books and enable virtual interaction by visiting any URL, it is not surprising that many responses focussed on efficiency and quick and easy access as reasons for implementing QR Codes in the law library. Table 5 above supports the view that 
libraries should indeed incorporate simple new technology which would enable patrons to reach information that they are interested in more easily than having to "type in a long URL with big fingers on a small keyboard" (McDonald 2012:2).

The responses to the survey are encouraging as they indicate that QR Codes should be used to enhance student learning and facilitate access to essential library resources. If this is not the case, the functionality of the codes will be undermined by a "lack of enthusiasm" (Elmore et al 2012: 34). One user who participated in this survey, for instance, said that they "come to the library to be productive, not engage in leisure activities using phones". Another voiced concern for the possibility of the QR Code replacing conventional ways of performing research. It is these kinds of misconceptions that the researcher tried to avoid by ensuring that the use of QR Codes adds value to the user's research in the library.

\section{Problems associated with this study}

The first setback experienced with this study relates to the application for ethics clearance. Having submitted the questionnaire to the Ethics Committee for feedback, the researcher was advised to make a formal application for ethics clearance as well as for access to students before approaching any library user. The applications entailed lengthy questions as well as the inclusion of the research proposal. Approval was granted only after the June Examination had been completed and with the commencement of the mid-year vacation. During this time the library appeared somewhat uninhabited and it is considered a blessing that the survey elicited more than 50 responses. In addition, it was intended for the online survey on the law website depicting the same questions to reach academics in the law faculty; however, the researcher was not granted consent to approach the faculty members as the ethics application was aimed at students only.

Secondly, as the research report was to be submitted on 27 July 2012, and students return for the second semester on 22 July 2012, the data for the first survey (needs analysis) needed to have been collated and evaluated by then. Fortunately, the submission date for this project was extended to 10 August 2012, which provided the researcher with a window period of 14 days with which to accumulate more responses. Despite the extra time, it still remained a challenge to raise awareness of QR Codes as well as persuade library users that these codes are beneficial to use. The timeframe for this project rendered it impossible to successfully integrate the use of QR Codes in the law library and to engage students efficiently with using the QR Codes for research. Consequently, the second survey can only be distributed to students after the research report has already been submitted. Hence this project is intended to build on and continue this pilot study, which could serve as a prototype for UCT Libraries. This report therefore entails a detailed discussion of the first step of the study, namely the needs assessment. 
Despite these problems, the needs assessment yielded some interesting data. The statistical data shows that law library patrons who own smartphones are eager to use QR Codes as an avenue for research. Many believe that QR Codes would provide a fast and efficient means of instructional technology when accessing library services. Furthermore the analysis of the survey is based on a relatively small sample of the law student body who, by their very participation in the questionnaire, show an active interest in QR Codes. Although the feedback from this study appears positive and promising, the challenge that remains is to evolve the QR Code into a sustainable technological mode for academic research in this library. Students should spontaneously scan the QR Codes in library holdings, group study rooms and on posters or notice boards, rather than rely on continual invitations from library staff. Feedback and statistics from the survey inform the researcher that much more advocacy is needed to alleviate this problem.

\section{Conclusions and recommendations}

It can be concluded at this early stage of the research that UCT libraries and others further afield should be encouraged to experiment with offering QR Code training and awareness programmes as well as training on using QR Codes as educational tools before engaging students actively with the use of QR Codes in the library. Students should be encouraged to overcome the barriers of new technology, such as those associated with the understanding and use of the QR Code. This reinforces the fact that it is crucial to understand the patron's knowledge of technology and research requirements, both of which can be produced via a needs analysis. The experience of this needs analysis could be a useful starting point for other UCT branch libraries who may wish to optimize their service models through the deployment of QR Codes.

From the viewpoint of progress being made in the mainstreaming of QR Codes internationally, the researcher is optimistic that QR Code strategies and initiatives will be placed on the agenda of South African academic libraries. As mentioned earlier, Mohamed (2009) emphasizes the significance of creating access to knowledge in the developing world and as proven by other case studies, the QR Code has internationally been delivering relevant content to library users successfully.

It is recommended that the researcher and other professional staff of the law library should introduce new and interesting methods which could generate more enthusiasm from students to actively use QR Codes:

1. The QR Code could link to video trailers of various lectures in the law faculty as well as those offering legal research training. Students who have missed their lectures or information literacy classes in the library could scan the code, watch the trailer, and be informed that the full lecture is available in the library. To circumvent copyright infringement, the lectures, which will have been loaded onto library desktop computers in the training room, can only be 
viewed and not downloaded. To achieve this, the need for a dedicated server may be negotiated and motivated for with the UCT ICTS Department.

2. In correspondence with the researcher, the author Andrew Walsh proposed that, since many students have smartphones, it could be more fruitful to first establish what information users would want to access from mobiles before making such information available online (Walsh 2012). Creating a mobile website to provide that information would ultimately serve the purpose for using QR Codes that will link to resources on that website. He advises that Ryerson University (http://m.library.ryerson.ca/) commenced this initiative a few years ago and that the student population provided positive feedback. This communication with Walsh encourages the researcher to pursue the endeavour to produce a mobile law library website.

Mobile phones represent the rapid acceleration in technological innovation and as clearly emphasized in Evans's publication, these technologies have created a "culture of participation". Our libraries are obligated to gain knowledge on how smartphones are used by our library patrons in order to facilitate this culture. Evans mentions that as the use of QR Codes become widespread, it increases the "information density" (Evans 2009:83) of library holdings and in turn increases communication between patrons. The future directions of the use of the QR Code for academic research is not yet entirely clear but this pilot study has indicated that it is imperative that continued support be given to ensure that its role in research develops successfully.

\section{Acknowledgements}

I would like to thank the Law students of the University of Cape Town (UCT) for taking part in this needs analysis. My sincere gratitude goes to Professor Christine Stilwell, University of KwaZulu-Natal (UKZN), for her invaluable guidance in this study. I am grateful for her constructive comments and encouragement which facilitated its publication. Much appreciation goes to Gwenda Thomas, Director of UCT Libraries who is affording me the opportunity to continue with this study and to Pamela Snyman, Manager of the Brand van Zyl Law Library for her patience and understanding. 


\section{References}

Ashford, R (2010) QR Codes and academic libraries: reaching mobile users. College and Research Libraries News. November: 526 - 530.

Barocas, J (2012) Why QR Codes won't last Available at: http://mashable.com/2012/02/15/qr-codes-rip

Ehlers, G (2012) Oliver Tambo Library, UP, via email, 31 May 2012.

Elmore, L. and Stevens, D (2012) The application of QR Codes in UK academic libraries. New Review of Academic Librarianship 18(1): 26-42, Available at: http://dx.doi.org/10.1080//13614533.2012.654679

Evans, W (2009) Building library 3.o: issues in creating a culture of participation. Oxford: Chandos.

Goodman, L (2012) Eight great ways to use QR Codes for marketing, Available at: http://marketingland.com/8-great-ways-to-use-qr-codes-for-marketing-5650

Griffey, J (2010), Mobile technology and libraries, London: Facet Publishing.

Hicks, A and Sinkinson, C (2011) Situated questions and answers: responding to library users with QR Codes. Reference and User Services Quarterly 51(1):6069.

Hutton, J (2011) Mobile phones dominate South Africa Available at: http://blog.nielsen.com/nielsenwire/global/mobile-phones-dominate-insouth-africa/

Jackson, Darla (2011) Thinking About Technology: Standard Bar Codes Beware Smartphone Users may prefer QR Codes. Law Library Journal 103: 153.

Kwanya, T, Stilwell, C and Underwood, P (2009) Library 2.0: revolution or evolution? South African Journal of Libraries and Information Science 75(1): 70-75.

Lippincott, J.K (2008) Mobile technologies; mobile users: implications for academic libraries Available

at: http://www.arl.org/bm doc/arl-br-261-mobile.pdf

McDonald, L (2012) Stupid is as stupid does: solving the "problem" of QR Codes and other emerging channels Available at: http://www.silverpop.com/blogs/email-marketing/qr-codes-emergingchannels.html

Mobile Pushes Internet to the Masses (2012) Available at: http://www.worldwideworx.com/mobile-pushes-internet-to-the-masses

Mohamed, S (2009) African Higher Education Research Online (AHERO): a model for sustainable academic research and development, In AAU (ed). Sustainable Development in Africa: The role of Higher Education Selected Papers 12th General Conference of the Association of African Universities, Accra, Ghana: Qualitype Limited: 69-81

Mullan, J (2012) Making molehills out of mountains: a look at some emerging technologies. Legal Information Management 12(1): 51-55.

QR Codes: Library Success - A best practice wiki (2012) Available at http://www.libsuccess.org/index.php?title=QR Codes 
Ramsden, A and Jordan, L (2008) The use of QR codes in education: a getting started guide for Academics Working paper. University of Bath. Available at: http://opus.bath.ac.uk11408

Robertson, C and Green, T (2012) Scanning the potential for using QR Codes in the classroom. TechTrends 56(2): 11-12.

Soy, S. K (1997) The case study as a research method. Unpublished paper, University of Texas at Austin, Available at: http://www.gslis.utexas.edu/ Ssoy/usesusers/l391d1b.htm

Stuart, D (2010) Web 3.0 promises changes for libraries. Research Information February/March 2010 Available at: http://www.researchinformation.info/features/feature.php?feature $\mathrm{id}=253$

The process of thematic analysis. Available at: http://subvista.wordpress.com/2010/03/25/new

Titcomb, A (2000) Needs analysis. ICYF Evaluation Concept Sheet, The University of Arizona. Available at: http://extension.arizona.edu/evaluation/sites/extension.arizona.edu.evaluati on/files/docs/needs.pdf

Tucker, A (2011) What are those checkerboard things? How QR codes can enrich student projects. Techdirections November: 14-16

Walsh, A (2012) University of Huddersfield Library, UK, via email, 4 July 2012.

Walsh, A (2010) QR Codes - using mobile phones to deliver library instruction and help at point of need. Journal of Information Literacy 4(1): 55-64

\section{About the author}

\section{Biography Of Shehaamah Mohamed}

Shehaamah Mohamed is South African and has lived in Cape Town since birth. She is a subject specialist librarian at the Brand van Zyl Law Library, University of Cape Town (UCT) where she is responsible for the legal research training of law students as well as the legal reference service of the Law Faculty. Having experienced and appreciated the use of the QR Code at other local university libraries, Shehaamah's interest in current mobile technologies was further enhanced through a project that she initiated at the law library involving the use of QR Codes. Her contribution to The Higher Education Technology Agenda (THETA) conference in Tasmania, Australia in April 2013 takes the form of a poster presentation which highlights the results of this project and student responses to using the QR code as a research tool.

Shehaamah received her Bachelor of Arts (BA), Library Science (B.Bibl), LLB and LLM degrees at the University of the Western Cape (UWC), South Africa. Her Phd research focuses on the use of mobile computing devices at higher education institutions and academic law libraries.

Author Contact details:

Email address: Shehaamah.Mohamed@uct.ac.za

Mobile Number: +2772 2006388 